\title{
Asian Monsoon Variation over the late Neogene-early Quaternary recorded by Anisotropy of Magnetic Susceptibility (AMS) from Chinese loess
}

Xingjun Xie $e^{a, b, c}$, Feng Xian ${ }^{a, b^{*}}$, Zhenkun $W u^{a, b}$, Xianghui Kong ${ }^{a, b}$, Qiufang Chang ${ }^{d, c}$

a State Key Laboratory of Loess and Quaternary Geology, Institute of Earth Environment, Chinese Academy of Sciences, Xi'an 710061, China

b Shaanxi Provincial Key Laboratory of Accelerator Mass Spectrometry and Application, Xi'an Accelerator Mass Spectrometry Center, Xi'an 710061, China

${ }^{c}$ University of Chinese Academy of Sciences, Beijing 100049, China

${ }^{\mathrm{d}}$ Key Laboratory of Salt Lake Resources and Chemistry, Qinghai Institute of Salt Lakes, Chinese Academy of Sciences, Xining 810008, China

* Corresponding author: xianf@ieecas.cn

\section{Abstract:}

This paper discusses the Anisotropy of Magnetic Susceptibility (AMS) records during late Neogene to early Quaternary from the Lantian loess section near the southern margin of the Chinese Loess Plateau. The AMS results for this site are shown to reflect variations in the direction of the paleomonsoon. The Lantian loess sediments are largely aeolian in origin, but also include a thin layer that exhibits secondary aqueous depositional features. The major ellipsoid axis AMS orientations in the loess samples indicate a pervasive Northwest-Southeast directional component since the late Neogene. Since that time, the W-E component gradually overtakes the $\mathrm{N}-\mathrm{S}$ component, which may explain the trend toward increased aridity during that time. Finally, a local heavy rainfall event seemingly occurred in the Lantian region about 2.6 Ma, which may have been responsible for the aqueous redeposition of sediments observed in $\mathrm{L}_{33}$ layer in this study.

Keywords: Neogene; Quaternary; Loess; Anisotropic of magnetic susceptibility; Monsoon 


\section{Introduction}

The loess-paleosol sequences of Chinese Loess Plateau which spans a broad region of central China provide continuous terrestrial archives of the climate changes for the past 2.6 Ma (An, 2000; Liu and Ding, 1998; Zhu et al., 2007). Further studies have confirmed that the paleoclimatic signals that were recorded by the climatic proxies from Chinese loess (e.g., magnetic susceptibility and grain size) can be well correlated to the marine oxygen isotope records (An et al., 2001; Ding et al., 2002; Kukla, 1987). Chinese loess has become one of the most important tools in studying paleoclimatic changes, along with the marine sediments and polar ice cores.

Anisotropy of Magnetic Susceptibility (AMS) is a fundamental physical characteristic of sediments that is caused by the ordered arrangement of magnetic particles (Hrouda, 1982; Rochette et al., 1992). AMS is a sensitive indicator of the magnetic fabric of sediments, perpetrated by wind. Consequently, paleowind directions can be investigated with AMS in sediments deposited over time (Zhang et al., 2010). In recent years, several studies using AMS to trace paleowind directions have been reported (e.g., Ge et al., 2014; Huang and Sun, 2005; Lagroix and Banerjee, 2002, 2004; Wang, 1998; Zhang et al., 2010; Zhu et al., 2004; Zhu et al., 2007). Most of these studies showed that the AMS of the sediments can exhibit a discernible directivity (Ge et al., 2014; Huang and Sun, 2005; Lagroix and Banerjee, 2002, 2004; Wang, 1998; Zhang et al., 2010; Zhu et al., 2004), except for an AMS study from Chinese loess formed in the late Neogene-early Quaternary (Zhu et al., 2007). To further examine the possibility of using AMS for paleomonsoon-direction reconstructions, we have investigated 1500 samples with high temporal resolution from the Lantian loess, deposited during the late Neogene-early Quaternary.

\section{General Setting}

The Lantian (Duanjiapo) loess section (about $34.2^{\circ} \mathrm{N}, 109.2^{\circ} \mathrm{E}$, Fig. 1) is located on the east slope of Bailuyuan loess tableland, which is in the southern part of the Chinese Loess Plateau. At present, this region is basically controlled by the Asian Monsoon climate, with a mean annual precipitation of $\sim 615 \mathrm{~mm}$ and a mean annual 
temperature of $\sim 13{ }^{\circ} \mathrm{C}$. Winters are relatively cold and dry under the influence of the East Asian winter monsoon, while summers are relatively warm and humid under the influence of the East Asian summer monsoon. The loess-palaeosol sequence in this region is $\sim 132 \mathrm{~m}$ thick and is underlain by $\sim 62 \mathrm{~m}$ of the Pliocene Red Clay deposits. The stratigraphic division of the sampled loess sequence is shown in Fig. 2a.

\section{Sampling and test methods}

To insure sample quality, large blocks unaffected by weathering were continuously sampled in the field. The hand-cut blocks of $\sim 15 \mathrm{~cm}$ in width and $\sim 20-30 \mathrm{~cm}$ in height were oriented in situ using a magnetic compass. After the blocks were air dried in the laboratory, both the powder sample and the cube sample $(2 \mathrm{~cm} \times$ $2 \mathrm{~cm} \times 2 \mathrm{~cm}$ ) were collected at $2 \mathrm{~cm}$ interval from the blocks. Geomagnetic azimuth was marked on every cube. A total of 750 powder samples and 750 cube samples at 2 $\mathrm{cm}$ interval were collected.

The magnetic susceptibility of the powder samples (10 g standard) were measured using a Bartington MS2 Double-frequency Magnetism Measurement Instrument, located at the Xi'an Accelerator Mass Spectrometry Center (Fig. 2b). The AMS of the cubed samples were measured using a Kappa Bridge MFK1A multi-frequency magnetic susceptibility instrument in the paleomagnetic laboratory, Institute of Earth Environment of CAS. Each sample was rotated and measured along three orthogonal planes, and the AMS ellipsoid was then calculated by the least-squares method (Zhang et al., 2010; Zhu et al., 2004). The anisotropy parameters that we obtained (Fig. 2c-g, where $\mathrm{c}$ is the mass magnetic susceptibility $\chi$ converted from measured volume susceptibility $\kappa_{\mathrm{m}}$ ) was calculated using software, following the method of Jelinek (1981).

Magnetic hysteresis loops, isothermal remanent magnetization (IRM) acquisition curves and back-field curves were determined for 14 samples from different layers of the section using a Model 3900 vibrating sample magnetometer (Princeton Measurements Corporation VSM3900, sensitivity: $0.5 \times 10^{-9} \mathrm{Am}^{2}$ ) in the paleomagnetic laboratory, Institute of Earth Environment of CAS. Every powdered 
raw sample of $\sim 0.2 \mathrm{~g}$ was firstly used to determine the hysteresis loops (maximum field: $1500 \mathrm{mT}$, step increment: $12 \mathrm{mT}$, averaging time: $100 \mathrm{~ms}$ ). Saturation magnetization $\left(M_{s}\right)$, saturation remanence $\left(M_{r s}\right)$ and coercive force $\left(B_{c}\right)$ were determined after correction for the paramagnetic contribution identified from the slope of loop at high fields. Subsequently, an isothermal remanent magnetization (IRM) was imparted from 0 to $1500 \mathrm{mT}$ (step increment: $10 \mathrm{mT}$, averaging time: 1000 $\mathrm{ms}$ ) and followed by demagnetization in stepwise backfield (0 to $-1500 \mathrm{mT}$, step increment: $-10 \mathrm{mT}$, averaging time: $1000 \mathrm{~ms}$ ) to obtain the coercivity of remanence $\left(\mathrm{B}_{\mathrm{cr}}\right)$.

\section{Results and discussion}

\subsection{Magnetic mineralogy}

IRM acquisition curves of representative samples from the loess and red clay sediments follow similar trajectories that reflect their similar characteristics in magnetic mineralogy (Fig. 3). All IRM acquisition curves undergo a major increase below $300 \mathrm{mT}$, which is consistent with the dominant contribution of low-coercivity magnetite and maghemite to the magnetic mineralogy. All the samples in Fig.3 are saturated below $1000 \mathrm{mT}$ except the sample at $830 \mathrm{~cm}$ (Fig. 3c) which is saturated at $1300 \mathrm{mT}$. The curves increase slightly above $300 \mathrm{mT}$, implying the presence of high-coercivity hematite. The IRM demagnetization curves (Fig. 3a, b, d, e, f) demonstrate that the reversed field applied to the $\mathrm{IRM}_{1500 \mathrm{mT}}$ can demagnetize the remanence when reaching $40 \mathrm{mT}$, supporting the dominance of low-coercivity magnetite. The sample at $830 \mathrm{~cm}$ required $50 \mathrm{mT}$ to demagnetize remanence (Fig. 3c), which is in agreement with the presence of hematite as suggested previously.

Fig. 4 shows magnetic hysteresis loops for representative samples from loess and red clay. All of the samples display a significant paramagnetic contribution (not shown in Fig. 4). After correction for the paramagnetic contribution, the hysteresis loop for the sample at $830 \mathrm{~cm}$ almost closes at $500 \mathrm{mT}$ (Fig. 4c), which reveals the existence of a high-coercivity hematite component in addition to the low-coercivity magnetite and maghemite component. The other samples show hysteresis loops that 
close below $500 \mathrm{mT}$, such as samples at depths of $316 \mathrm{~cm}, 600 \mathrm{~cm}, 1000 \mathrm{~cm}, 1158 \mathrm{~cm}$ and $1430 \mathrm{~cm}$ (Fig. 4a, b, d, e, f). In these samples, the dominant magnetic mineral components are low-coercivity magnetite and maghemite. In summary, the magnetic mineralogy of the Lantian loess-red clay sequence is dominated by low-coercivity magnetite and maghemite, high-coercivity hematite co-exists in the samples as a minor component.

\subsection{Timescale}

Sun et al. (2006) have published a robust timescale for Chinese loess through an orbital tuning method. For this study, the Lantian sedimentary sequence timescale was derived by correlating our magnetic susceptibility curve with that of Sun et al. (2006).

We selected control points to constrain the time frame of the Lantian section. The control points are mainly located in transition layers between loess and paleosol or loess and red clay, so that each time interval shares a roughly constant sedimentation rate under the same climatic conditions. By assuming that the sedimentation rate of each time interval is constant, a continuous age model can be calculated. The timescale is shown in Fig. 5.

\subsection{AMS}

The low field AMS is generally described in the sample by an oriented ellipsoid with maximum $\left(K_{\max }\right)$, intermediate $\left(K_{\text {int }}\right)$, and minimum $\left(K_{\min }\right)$ axes of magnetic susceptibility (Zhang et al., 2010). The usual anisotropy parameters include lineation $L\left(L=K_{\max } / K_{\text {int }}\right)$, foliation $F\left(F=K_{\text {int }} / K_{\text {min }}\right)$, the degree of anisotropy $P\left(P=K_{\max } /\right.$ $\left.K_{\min }\right)$ and the shape factor $T\left(T=\left[2 \ln \left(K_{\text {int }}\right)-\ln \left(K_{\max }\right)-\ln \left(K_{\min }\right)\right] /\left[\ln \left(K_{\max }\right)-\ln \right.\right.$ $\left.\left.\left(K_{\min }\right)\right]\right)$. A number of studies (e.g., Liu et al., 2001; Liu et al., 1992; Qiang et al., 2005; Zhu et al., 1996) and our magnetic mineralogy analyses show that magnetite and maghemite are the dominant magnetic minerals in both loess and red clay sediments, and the magnetite can show AMS by its shape (Gong et al., 2007; Hrouda, 1982; Liu et al., 1990), which indicates that the AMS measurements of loess and red clay are comparable. The magnetic susceptibility curves and AMS parameters of Lantian 
loess-red clay sequence are shown in Fig. 2.

Most of the samples exhibit a characteristic of $1.002 \leq P \leq 1.032$, typical of aeolian sediments (Liu et al., 1988, 1990). There is also a high linear correlation between $P$ and $F\left(R^{2}=0.96\right)$ that indicates that foliation is the dominant factor influencing AMS. $L$ values in Quaternary deposits are relatively low, as compared to the Neogene deposits, and the curves of $F$ and $P$ in Quaternary deposits also shows a wider fluctuation than those of the Neogene deposits. Changes between the late Neogene and early Quaternary are due to changes in climate.

We further divided the magnetic susceptibility curves and anisotropy records into several stages based on lithologic changes within the loess strata (Fig. 2: shown as alternating shaded and non-shaded areas). We observe a persistent $\sim 30-60 \mathrm{~cm}$ offset between the mass magnetic susceptibility and the shape $(T)$, degree $(P)$, foliation $(F)$ and lineation $(L)$ parameters (Fig. 2), rarely reported before. We cannot explain this phenomenon at present, although it does not affect our further analysis in this paper.

There are some prominent characteristics observed in the records. The first is the $T$ curve, which shows significant fluctuations during warm stages (Fig. 2d), while the values for $P$ and $F$ (Fig. 2e, f) remain relatively constant. This suggests that there may be similar monsoon patterns during warm periods of the early Quaternary and that of the late Neogene, whose climate is considered to be relatively warm and humid (Ding et al., 1997; Sun et al., 2001). In contrast, quite different characteristics of anisotropy parameters are observed in loess (the unshaded areas in Fig. 2). The curve of $T$ fluctuated slightly in these periods with an approximate value of " 1 ", which means that the shapes of the AMS ellipsoids are mainly oblate spheroids. Meanwhile, the values of $P$ and $F$ during the relatively cold (unshaded) periods are comparatively higher than during warm periods. These differences between warm and cold periods suggest that the changes in the paleomonsoon pattern are distinct to be detected by AMS.

In addition, there is an unusual layer (about $868 \mathrm{~cm}$ in the lower part of $\mathrm{L}_{33}$ ) with a high value of $P, F$ and $L$ (Fig. 2e, f, g) in the loess sequence. The high value of $P, F$ and $L$ certifies a well ordered arrangement of magnetic particles, hence there should 
be a strong driving force responsible for this layer. The unusual layer is $\sim 6-8 \mathrm{~cm}$ thick, and the upper and lower boundaries are distinctive in the field (Fig. 6). They belong to silty clay deposits which are different from the upper and lower bounding strata. Based on the measured data $(1.032 \leq \mathrm{p} \leq 1.064)$ of samples from this unusual layer, it belongs to a water-lain loess (Liu et al., 1988, 1990). According to the timescale of the loess sequences we obtained, the age of the water-lain layer is about 2.6 Ma. This suggests the possibility of local heavy rainfall in the early Quaternary. Furthermore, according to the preliminary result of remanence measurements (thermal demagnetization, unpublished), the water-lain loess layer was deposited in the period when the Gauss-Matsuyama geomagnetic reversal happened. Perhaps there is a link between geomagnetic reversals and paleoprecipitation.

In principle, wind directions can be inferred by studying AMS properties of sediments. For example, the $D-K_{\max }$ (declination of $K_{\max }$ ) of loess has a very good correlation with wind direction (Wu et al., 1998; Zhu et al., 2004). In order to understand changes in paleomonsoon wind directions we constructed stereographic projections of $K_{\max }$ and $K_{\min }$ and rose diagrams of $K_{\max }$ of each layer (Fig. 7). Before we constructed the rose diagrams of $K_{\max }$, we eliminated samples for which $\varepsilon_{12}<22.5^{\circ}$ ( $\varepsilon_{12}$ is the $95 \%$ confidence ellipse of $K_{\max }$ in the plane joining $K_{\max }$ and $K_{\text {int }}$ ) or $I-K_{\min }<70^{\circ}$ (inclination of $K_{\min }$ ) following the methods of Zhu et al. (2004) and Zhang et al. (2010).

As shown in Fig. 7, the $D-K_{\max }$ of the samples generally showed a NW-SE direction, except for layer $\mathrm{L}_{34}$. This supports the interpretation that the AMS results from loess deposited in the late Neogene-early Quaternary reflect the direction of the paleomonsoon. The W-E wind direction component gradually becomes dominant over the N-S component since the Neogene, into the Quaternary. This may reflect a change in monsoon pattern and this change may have weakened the transport of vapor from tropical and subtropical source zones to the Loess Plateau. From the view point of climate, the wind directions recorded by a typical loess that was deposited during cold periods is more concentrated and dominant, which may indicate that the monsoon pattern is relatively stable in the cold periods on the Loess Plateau. 
From the stereographic projection of $K_{\max }$ and $K_{\min }$, the distribution of $K_{\min }$ points for typical loess sediments (Fig. $7 \mathrm{l}, \mathrm{m}$ ) are very concentrated, indicating that the sediments are relatively undisturbed. There was a relatively stable environment with a poor vegetation cover at that time. The distribution of $K_{\min }$ points from paleosol samples (Fig. 7a, b) are relatively dispersed, which may be related to changes in the wind field, and the disturbance of the plant roots during those periods. The $K_{\min }$ points of Neogene $\mathrm{S}_{33}$ (Fig. 7c) and red clay (Fig. 7d) present a high dispersal degree, which may reflect that a well-developed vegetation cover on the Bailuyuan during the late Neogene, and pervasive disturbance of plant roots. In addition, the relatively warm and humid climatic conditions in the late Neogene (Ding et al., 1997; Sun et al., 2001) could directly cause the disturbances of local superficial deposits on the Loess Plateau through raindrops.

\section{Conclusions}

Previous AMS studies have focused on the environmental implications of Quaternary loess, while environmental implications of the underlying Mio-Pliocene red clay AMS remain poorly studied. In this study, our AMS investigations on loess sediments formed in the transitional period from the Neogene to the Quaternary show predominantly aeolian deposition, except for a thin layer may belong to the alluvial sedimentation. The $D-K_{\max }$ of the samples show a pervasive NW-SE component that we interpret as a reflection of paleomonsoon direction. This finding contrasts with the result of Zhu et al. (2007). Our results show that the W-E wind direction component gradually overtakes the $\mathrm{N}-\mathrm{S}$ component as the dominant component from the late Neogene to the Quaternary, and we suggest that this may be an important reason why aridity became enhanced over that period. As the paleosols and red clay may have been disturbed more or less after they deposited at that time, we suggest caution in the use of AMS to trace the paleomonsoon direction from those deposits.

The variation of AMS parameters is basically correlated with lithologic change, although there are apparent offsets between the AMS parameters and lithostratigraphy. Possible forcing mechanisms need to be studied in the future. Finally, we note an 
unusual water-lain layer with a thickness of $\sim 6-8 \mathrm{~cm}$, which may suggest a heavy rainfall event or period in the Lantian region about 2.6 Ma.

\section{Acknowledgments}

We are grateful to the anonymous reviewers for their insightful comments on an early version of this manuscript. We are very grateful to Prof. W. J. Zhou for her support to this study. And we thank H. J. Gong, W. Jing, S. G. Wu, M. Hu, and L. P. Jiang for their help in the field and X. K. Qiang, Z. H. He, H. Zhao, T. Chen, P. Zhang and X. B. Gao for their help during laboratory measurements. This work was jointly supported by National Science Foundation of China (No. 41230525 \& 41203019), Major National Scientific Research Projects (2013CB955901), and State Key Laboratory of Loess and Quaternary Geology, Institute of Earth Environment, CAS (No. SKLLQG1133).

\section{References}

An, Z.S., 2000. The history and variability of the East Asian paleomonsoon climate. Quaternary Science Reviews 19, 171-187.

An, Z.S., Kutzbach, J.E., Prell, W.L., Porter, S.C., 2001. Evolution of Asian monsoons and phased uplift of the Himalayan Tibetan plateau since Late Miocene times. Nature 411, 62-66.

Ding, Z.L., Derbyshire, E., Yang, S.L., Yu, Z.W., Xiong, S.F., Liu, T.S., 2002. Stacked 2.6-Ma grain size record from the Chinese loess based on five sections and correlation with the deep-sea $\delta^{18} \mathrm{O}$ record. Paleoceanography 17, 1033

Ding, Z.L., Sun, J.M., Zhu, R.X., Guo, B., 1997. Eolian origin of the Red Clay deposits in the Loess Plateau and implications for Pliocene climatic changes. Quaternary Sciences 17, 147-157 (in Chinese with English Abstract).

Ge, J.Y., Guo, Z.T., Zhao, D.A., Zhang, Y., Wang, T., Yi, L., Deng, C.L., 2014. Spatial variations in paleowind direction during the last glacial period in north China reconstructed from variations in the anisotropy of magnetic susceptibility of loess deposits. Tectonophysics 629, 353-361. 
Gong, H.J., Zhang, Y.X., Yue, L.P., Zhang, R., Wang, W., 2007. Sedimentological Significance of the Magnetic Fabric of the Neogene Red Clay in Lingtai, Gansu Province. Acta Sedimentologica Sinica 25, 437-444 (in Chinese with English Abstract).

Kukla, G., 1987. Loess Stratigraphy in Central China. Quaternary Science Reviews 6, 191-219.

Hrouda, F., 1982. Magnetic anisotropy of rocks and its application in geology and geophysics. Geophysical Surveys 5, 37-82.

Huang, X.G., Sun, J.M., 2005. Study of the magnetic fabrics in Chinese loess-paleosols since the last interglacial: implication of the paleowind direction. Quaternary Sciences 25, 516-522 (in Chinese with English Abstract).

Jelinek, V., 1981. Characterization of the magnetic fabric of rocks. Tectonophysics 79, T63-T67

Lagroix, F., Banerjee, S.K., 2002. Paleowind directions from the magnetic fabric of loess profiles in central Alaska. Earth and Planetary Science Letters 195, 99-112.

Lagroix, F., Banerjee, S.K., 2004. The regional and temporal significance of primary aeolian magnetic fabrics preserved in Alaskan loess. Earth and Planetary Science Letters 225, 379-395.

Liu, T.S., Ding, Z.L., 1998. Chinese loess and the paleomonsoon. Annual Review of Earth and Planetary Sciences 26, 111-145.

Liu, X.M., An, Z.S., Rolph, T., Qiang, X.K., Hesse, P., Lu, H.Y., Zhou, J., Cai, Y.J., 2001. Magnetic properties of the Tertiary red clay from Gansu Province, China and its paleoclimatic significance. Science in China Series D: Earth Sciences 44, $635-651$.

Liu, X.M., Shaw, J., Liu, T.S., Heller, F., Yuan, B.Y., 1992. Magnetic mineralogy of Chinese loess and its significance. Geophysical Journal International 108, 301-308.

Liu, X.M., Xu, T.C., Liu, T.S., 1988. The Chinese loess in Xifeng, II. A study of anisotropy of magnetic susceptibility of loess from Xifeng. Geophysical Journal 
92, 349-353.

Liu, X.M., Xu, T.C., Liu, T.S., 1990. Anisotropy of magnetic susceptibility and origin of the Chinese loess and its significance to the Quaternary research. Science in China (Series B) 33, 235-245

Qiang, X.K., An, Z.S., Li, H.M., Chang, H., Song, Y.G., 2005. Magnetic properties of Jiaxian red clay sequences from northern Chinese Loess Plateau and its paleoclimatic significance. Science in China Series D: Earth Sciences 48, 1234-1245.

Rochette, P., Jackson, M., Aubourg, C., 1992. Rock magnetism and the interpretation of anisotropy of magnetic susceptibility. Reviews of Geophysics 30, 209-226.

Sun, Y.B., Clemens, S.C., An, Z.S., Yu, Z.W., 2006. Astronomical timescale and palaeoclimatic implication of stacked 3.6-Myr monsoon records from the Chinese Loess Plateau. Quaternary Science Reviews 25, 33-48.

Sun, Y.B., Sun, D.H., An, Z.S., 2001. Paleoclimatic implication of frequency dependent magnetic susceptibility of red clay-loess-paleosol sequences in the Lingtai profile. Geological Journal of China Universities 7, 300-306 (in Chinese with English Abstract).

Wang, J.L., 1998. The anisotropy of loess magnetic susceptibility in the northeastern fringe of Qinghai-Xizang Plateau as an indicator of palaeowind direction. Chinese Geographical Science 8, 85-90.

Wu, H.B., Chen, F.H., Wang, J.M., Cao, J.X., Zhang, Y.T., 1998. Study on the relationship between magnetic anisotropy of modern eolian sediments and wind direction. Chinese Journal of Geophysics 41, 811-817 (in Chinese with English Abstract).

Yang, S.L., Ding, Z.L., 2010. Drastic climatic shift at $~ 2.8 \mathrm{Ma}$ as recorded in eolian deposits of China and its implications for redefining the Pliocene-Pleistocene boundary. Quaternary International 219, 37-44.

Zhang, R., Kravchinsky, V.A., Zhu, R., Yue, L., 2010. Paleomonsoon route reconstruction along a $\mathrm{W}-\mathrm{E}$ transect in the Chinese Loess Plateau using the anisotropy of magnetic susceptibility: Summer monsoon model. Earth and 
Planetary Science Letters 299, 436-446.

Zhu, R.X., Liu, Q.S., Jackson, M.J., 2004. Paleoenvironmental significance of the magnetic fabrics in Chinese loess-paleosols since the last interglacial $(<130 \mathrm{ka})$. Earth and Planetary Science Letters 221, 55-69.

Zhu, R.X., Pan, Y.X., Ding, Z.L., 1996. Magnetic property of red clay. Quarternary Sciences 16, 232-238 (in Chinese with English Abstract).

Zhu, R.X., Zhang, R., Deng, C.L., Pan, Y.X., Liu, Q.S., Sun, Y.B., 2007. Are Chinese loess deposits essentially continuous? Geophysical Research Letters 34, L17306

Zhu, Y.M., Zhou, L.P., Zhang, S.H., 2007. A preliminary study on anisotropy of magnetic susceptibility of the late Pliocene-early Pleistocene aeolian deposits in northern China. Quaternary Sciences 27, 1009-1015 (in Chinese with English Abstract). 


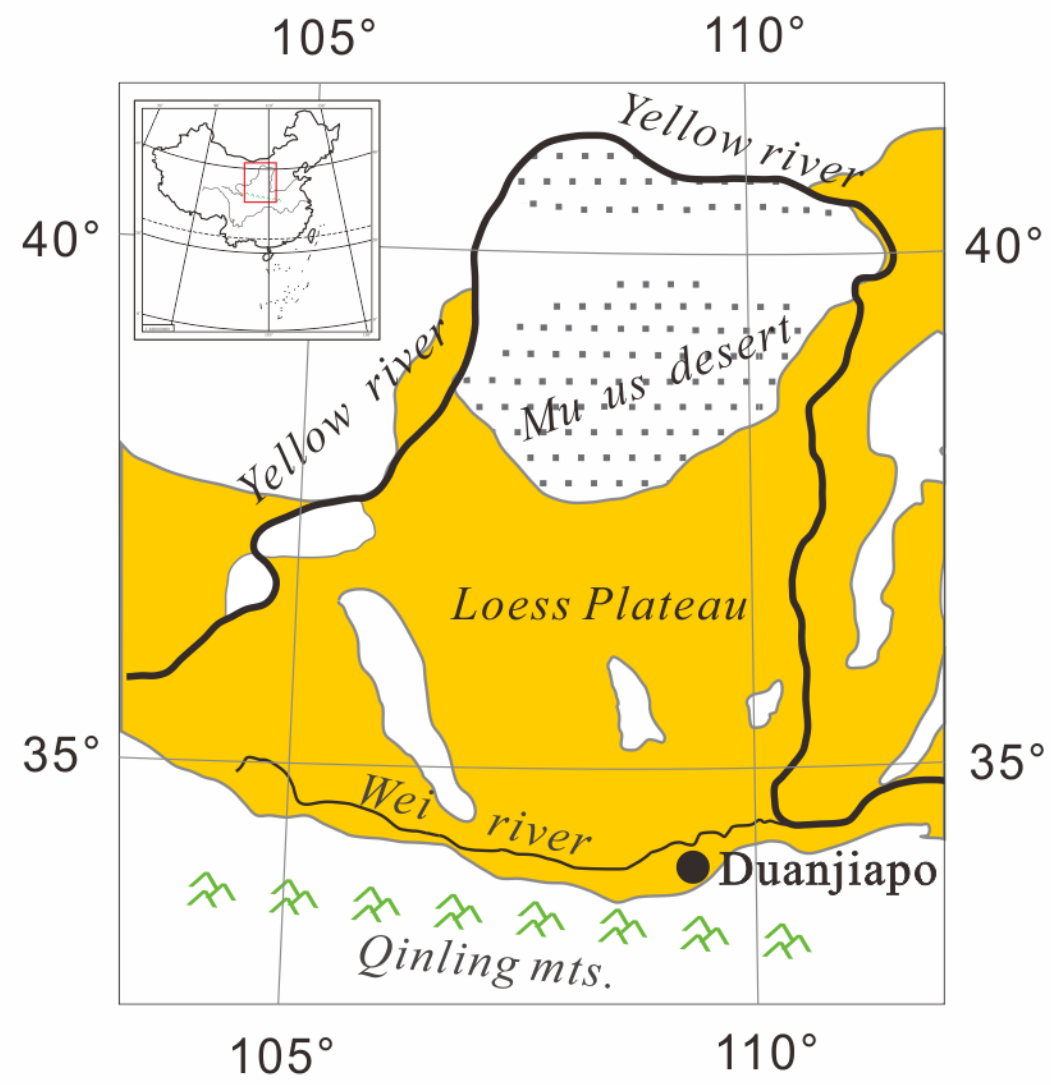

Fig. 1 Location of Duanjiapo section, Lantian, China. 


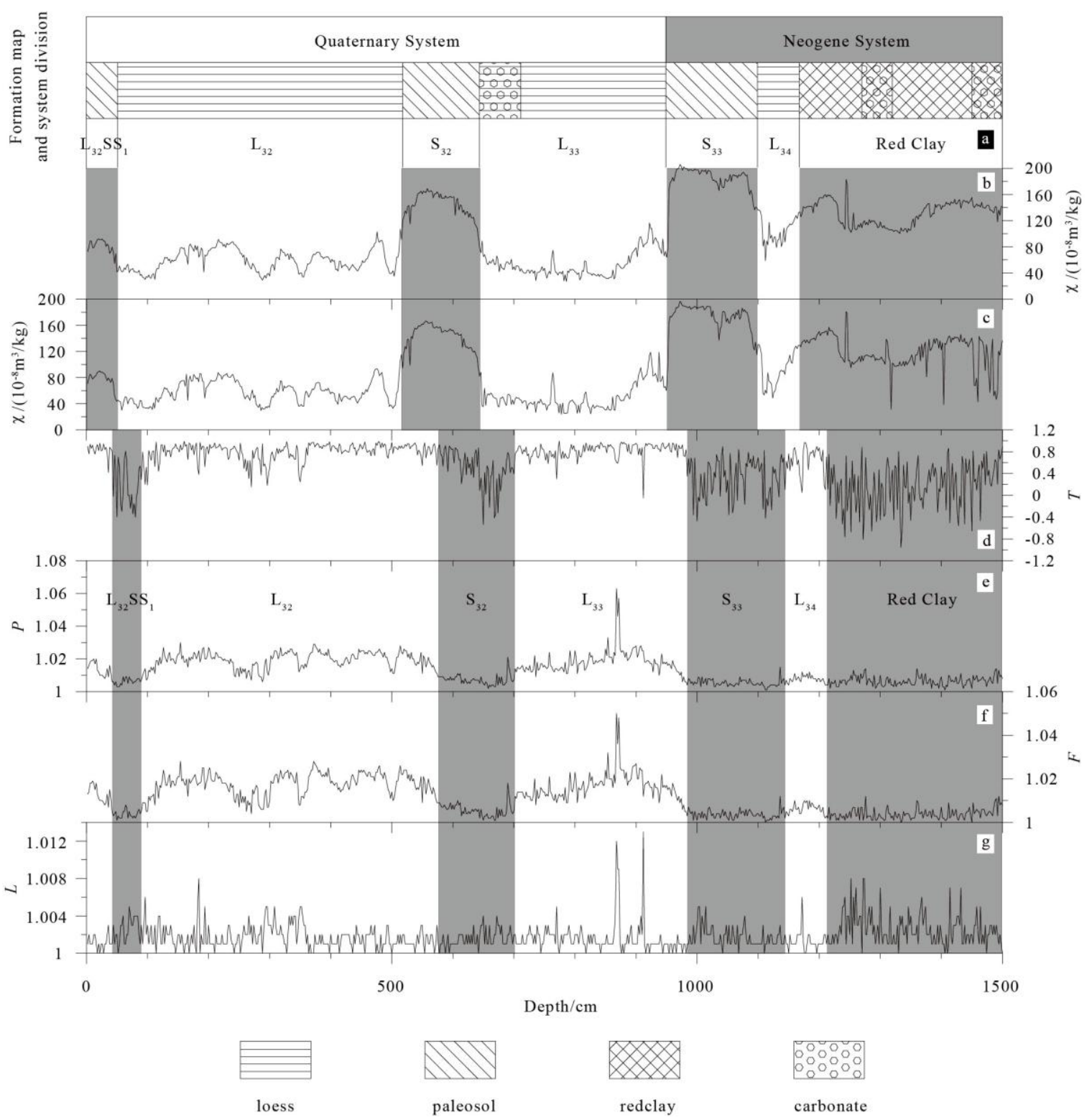

Fig. 2 System division of the sampled loess sequence in Lantian (a), stratigraphic division based on Yang and Ding (2010). The magnetic measurement results of loess specimens from this section are shown as a function of relative depth: mass magnetic susceptibility (b); mass magnetic susceptibility calculated from volume susceptibility (c); AMS shape parameter curve (d); AMS degree curve (e); magnetic foliation curve (f); magnetic lineation curve (g). Warm stages are denoted as shaded bars. 

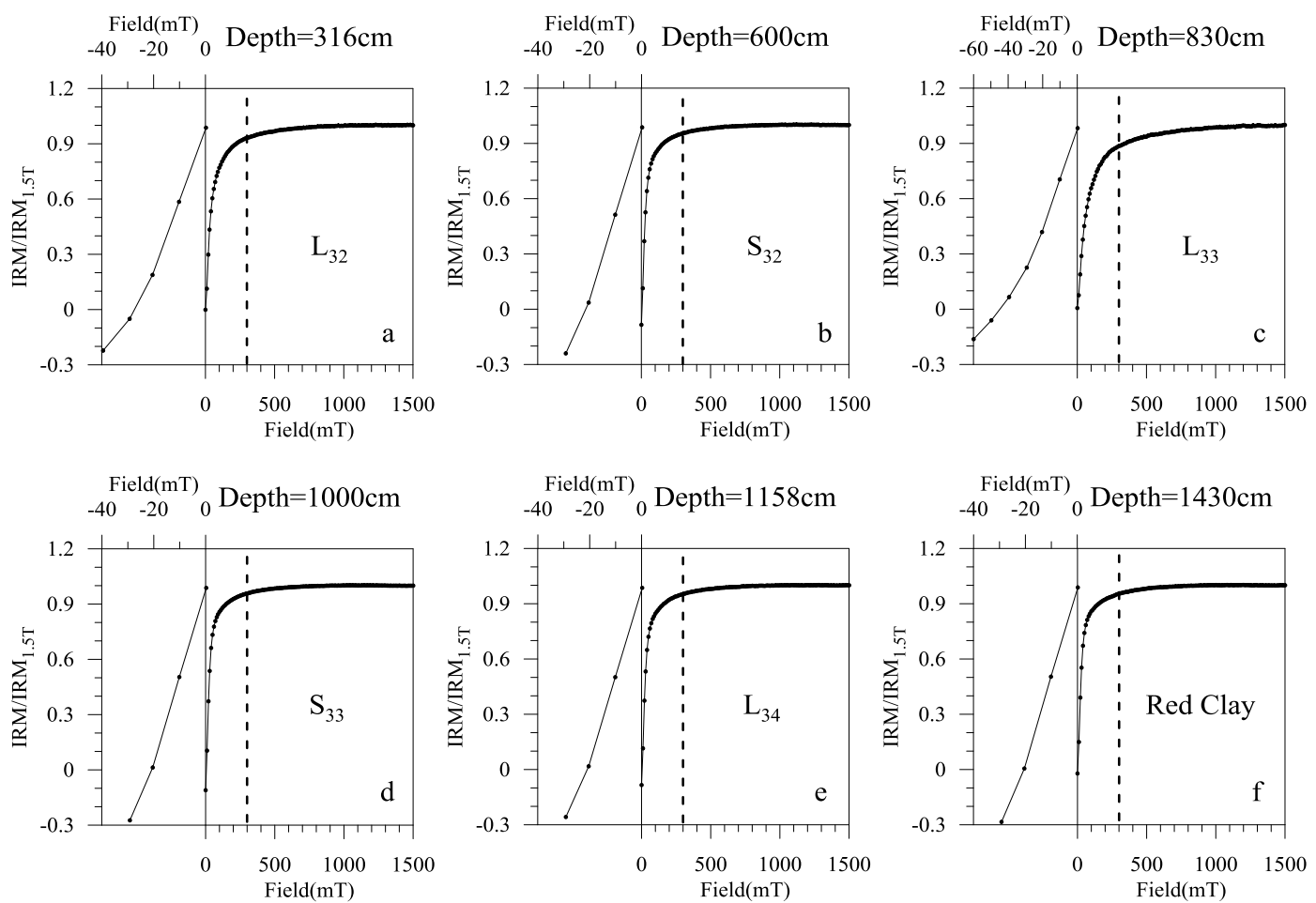

Fig. 3 Isothermal Remanent Magnetization (IRM) curves for selected samples from the Lantian (Duanjiapo) section. The dashed vertical lines at $300 \mathrm{mT}$ are shown to aid distinction between low- and high-coercivity portions of the IRM curves. 

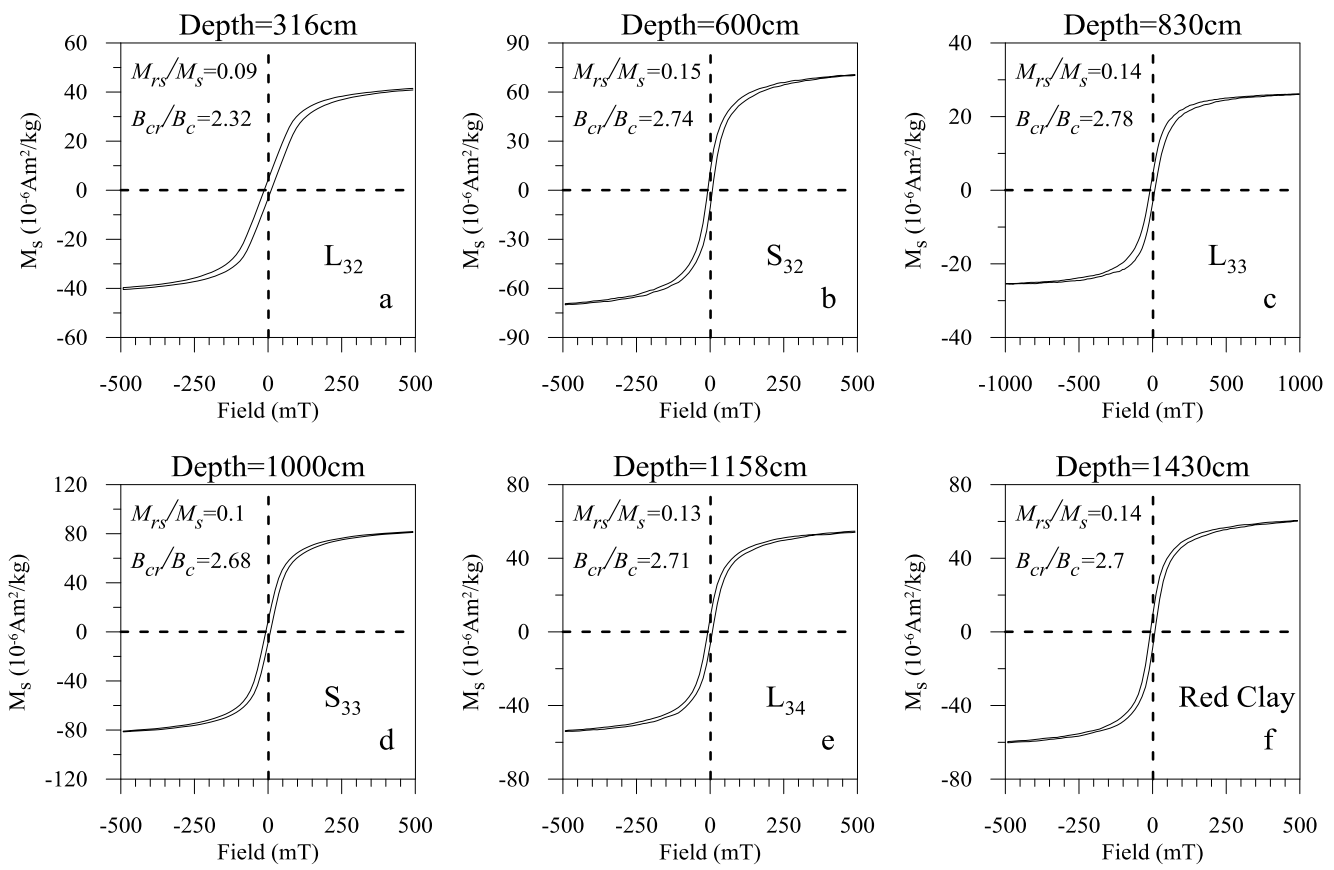

Fig. 4 Hysteresis loops for selected samples from the Duanjiapo section, Lantian, China 


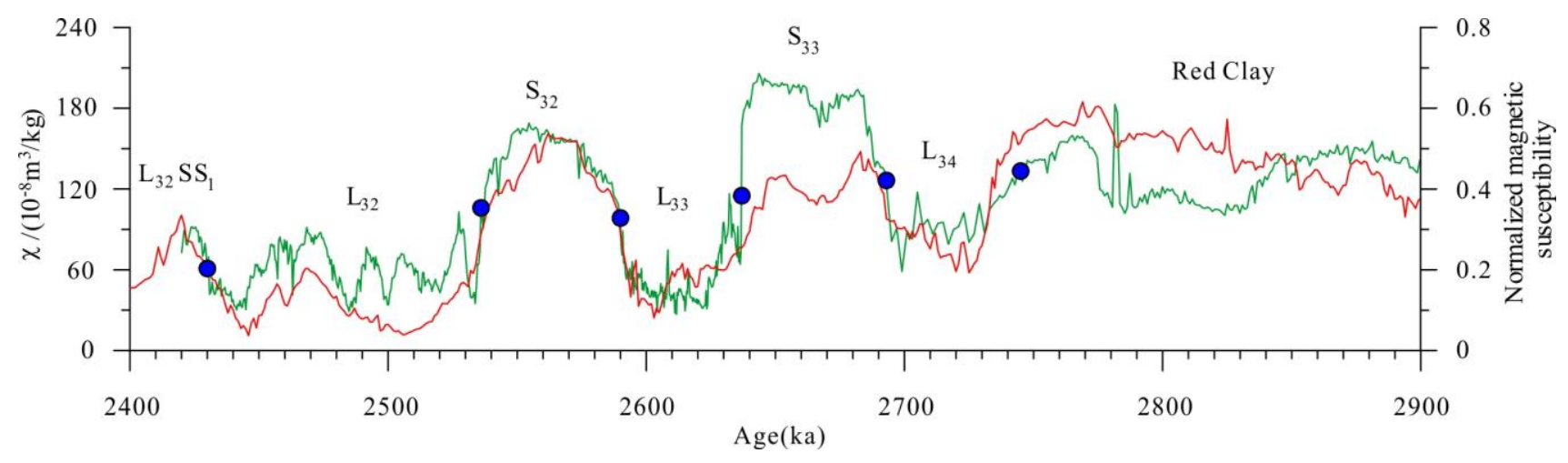

Fig. 5 Comparison of the magnetic susceptibility-age curve of the Duanjiapo section (green) and part of the normalized susceptibility-age curve (red) of Sun et al. (2006). The blue dots are time control points we chose 


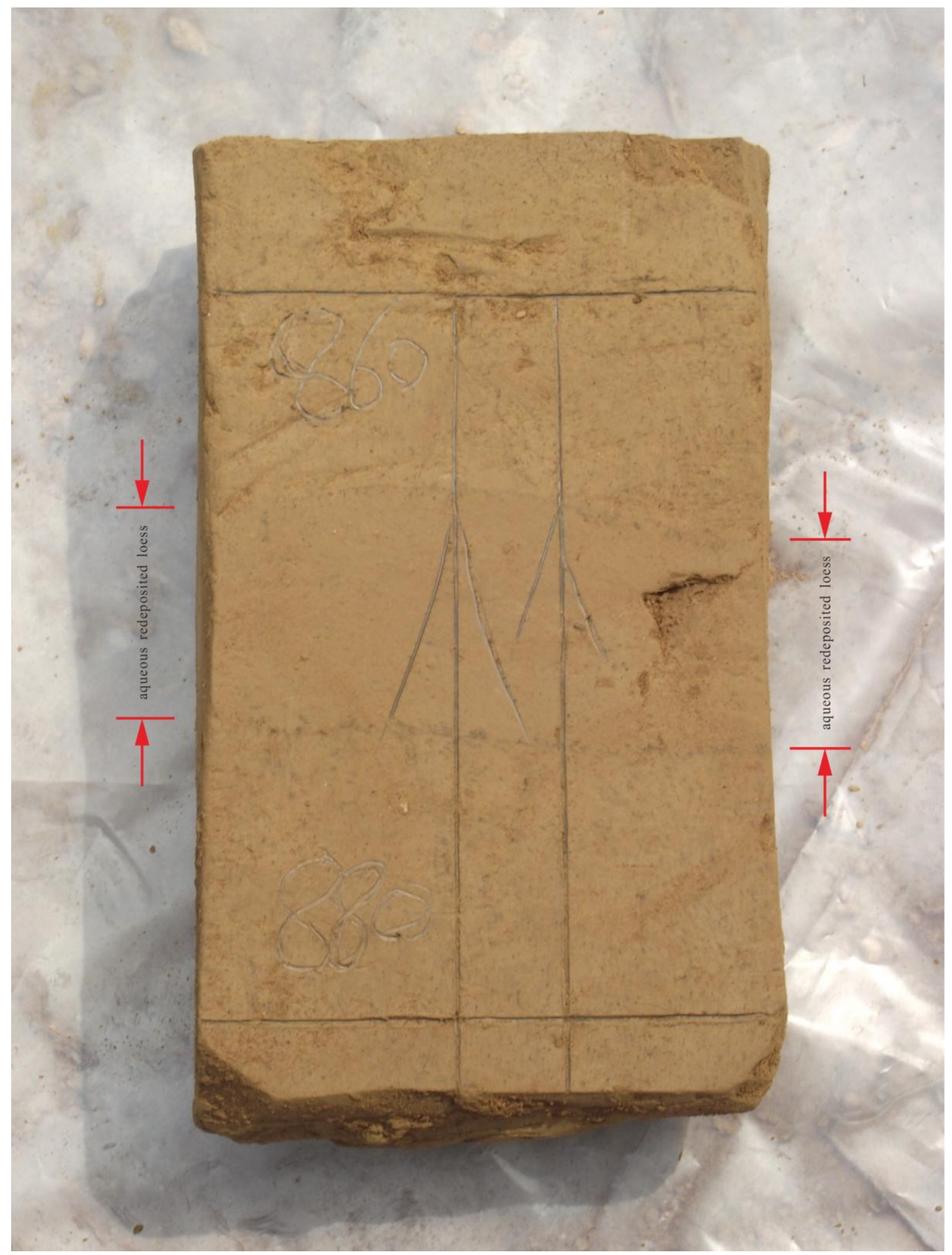

Fig. 6 Loess sample showing alluvial features. 


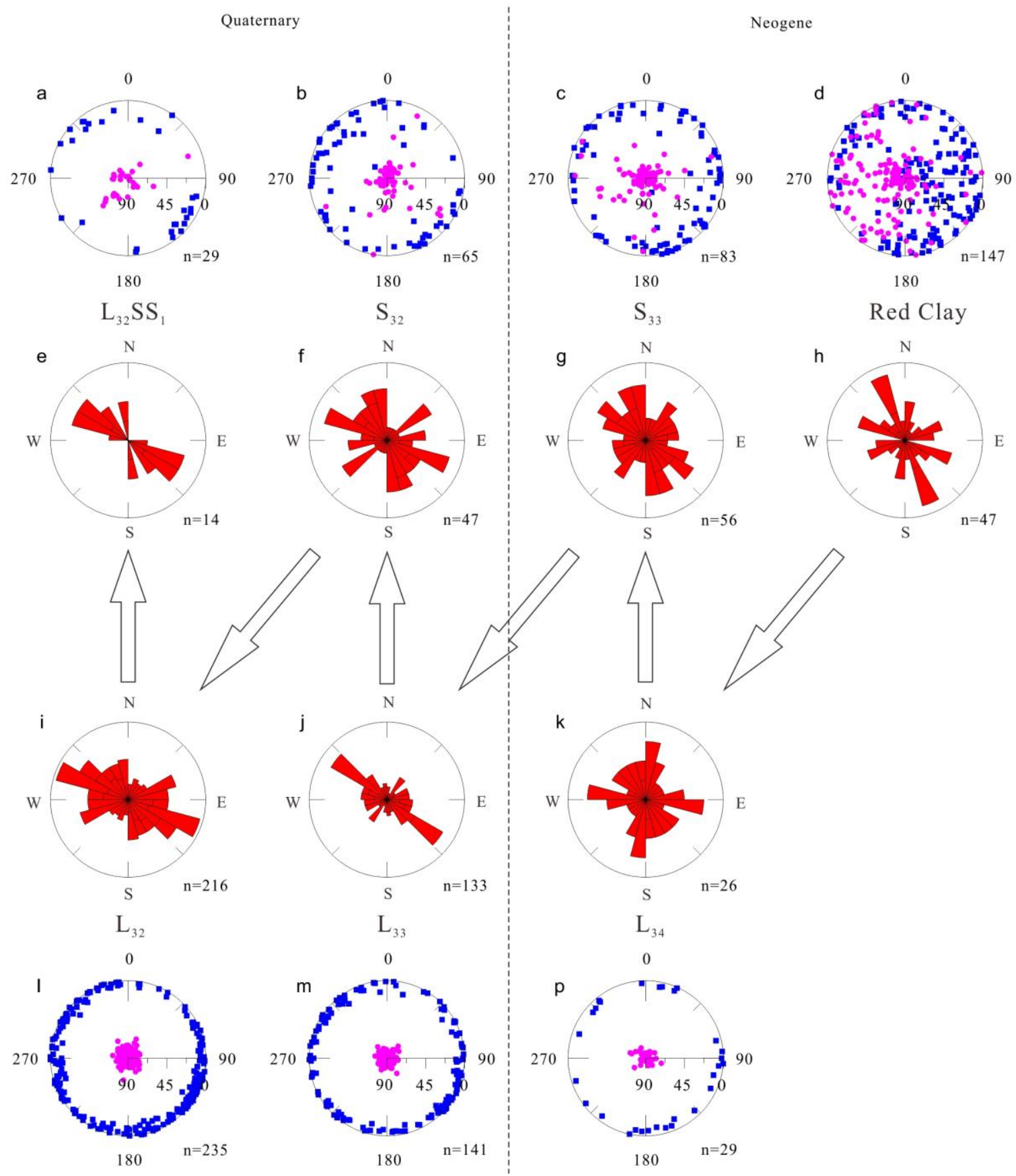

Fig. 7 AMS results for the Lantian section: (a), (b), (c), (d), (l), (m), and (p) shown as stereographic projections (bedding coordinates) of principal susceptibility axes $K_{\max }$ (blue squares) and $K_{\text {min }}$ (pink dots). Samples are from $\mathrm{L}_{32} \mathrm{SS}_{1}, \mathrm{~S}_{32}, \mathrm{~S}_{33}$, red clay, $\mathrm{L}_{32}, \mathrm{~L}_{33}$ and $\mathrm{L}_{34}$ layers in the Lantian section. Rose diagrams (bidirectional) of $K_{\max }$ are shown for samples (e) - (k), from layers $\mathrm{L}_{32} \mathrm{SS}_{1}, \mathrm{~S}_{32}, \mathrm{~S}_{33}$, red clay, $\mathrm{L}_{32}, \mathrm{~L}_{33}$ and $\mathrm{L}_{34}$. ' $\mathrm{n}$ ' is the total number of samples included for each analysis. These rose diagrams show progressive changes with the development of the stratum (the arrows indicate the history of development of the stratum). The Neogene and Quaternary periods are separated by a dashed line. 